\title{
The Effect of the Flipped Learning Strategy in Science Teaching on Developing the Motivation to Learn among Primary School Students in Jordan
}

\author{
Manal Abdul Karim Al-Momani \\ Department of Educational Sciences, \\ Ajloun University College, \\ Al-Balqa Applied University, \\ As-Salt, Jordan
}

DOI: https://doi.org/10.36941/jesr-2022-0012

\begin{abstract}
This study aimed to investigate the impact of the flipped learning strategy on developing motivation to learn, and to achieve this goal; the study sought to answer the following question: What is the flipped learning strategy's effect on developing the motivation to learn among 7thgrade students in the science subject compared to the usual method? The study sample was chosen by the intentional method, as the number of the sample reached (80) female students of the seventh grade at the Ebein Secondary School in the Ajloun Education Directorate. The study was divided into two groups. The first consisted of (40) students who studied using the flipped learning strategy, and the second consisted of (40) students also studied in the usual way. To achieve the goal of the study, the researcher prepared the five-stage learning motivation scale. The study showed the following result. A significant difference $(0.05 \leq \alpha)$ was found due to the use of the flipped learning method in testing motivation to learn and in favor of the experimental group.
\end{abstract}

Keywords: Flipped Learning Strategy, Science Teaching, Motivation, Primary School Students

\section{Introduction}

The science education process is witnessing a great interest and continuous development locally and internationally that has led to a radical transformation in the philosophy and methodology of learning and teaching science to become more effective in keeping pace with the characteristics and requirements of this era. To improve the level of learning and teaching science and develop students' abilities and skills to acquire scientific knowledge attractively and more comprehensively.

The constructivist theory has focused on the internal factors that affect the learning process that takes place within students' minds while they face educational situations. Such as previous knowledge, abilities and motivation to learn as the researcher believes that acquiring knowledge is an active and continuous process during which adjustments are made in students' cognitive structures through their self-organization mechanisms for new knowledge in line with their previous knowledge (Ayesh, 2004).

Motivation is considered one of the factors that direct and activate behavior towards achieving goals. It works on selecting and defining the activity that the student wishes to implement (Rashid, 
2005), where the process of stimulating students' motivation to learn science is an important and complicated process due to the difference in their mental and social structures (Al-Huwaidi, 2005).

The problem that science education suffers from lies in the aspect related to teaching models and strategies and methods used by teachers as they present the teaching-learning materials in most cases in a traditional, dry and dull way and this resulted in low results in the level of educational attainment and a lack of students' motivation towards learning science. It led to the formation of negative trends towards the school, and what is related to it as the best types of education are that education that is mixed with fun that generates a beautiful desire for knowledge and educational videos help teachers make class experiences more fun and more lively. As the world entered the digital age stage, technologies developed and became accessible to the general public, including teachers and students. Among these technologies are e-mail, mobile phones and tablets, which contributed to the development of the educational process and the use of technology in the learning and teaching processes led to the emergence of flipped learning, whose idea relates to what is done at home within the traditional learning is done during the class or classroom lecture and that what is done during the class or classroom lecture in traditional learning is done at home (Al-Feki, 2011).

Therefore, the adoption of modern teaching models, such as the flipped learning, which aims to create a sound cognitive structure for students, has become necessary to increase their motivation towards learning science.

The flipped learning strategy is one of the essential strategies that appeared in the current era, which mainly depends on keeping pace with technology and changing the traditional teaching and learning pattern. Numerous studies have indicated the importance of using such a strategy as the study of (Butt, 2014), the results of which showed a clear effect of the flipped learning strategy on student development to achieve the educational process's goals to achieve.

Marco (Marco, 2010) defined flipped learning as a teaching strategy that makes the student do the traditional teaching style by himself. The student is asked to read part of the textbook at home and study it through the available learning resources. As video lessons are prepared in advance by the teacher, after that the student is discussed in the class the next day, and he practices several activities with his colleagues and assesses the extent of his mastery of the topic.

Where Brame (2013) defined the flipped learning strategy as what is done at home within the traditional learning method is done during the classroom and what is done in the classroom is done at home. Thus, the student is exposed to the academic material outside the classroom, whether through an educational video that the teacher records to explain a specific lesson or through readings related to the lesson's topic.

Al-Shahrani (2014) defines it as "a strategy based on changing the nature of teaching, making the student watch lessons outside the classroom via YouTube at any time and place, and making the classroom a place for dialogue, discussion and solving assignments." What distinguishes the flipped learning strategy it provides interactive activities in the classroom that focus on various cognitive skills, provides students with the freedom to choose time for learning, and provides immediate feedback from teachers, in addition to that stimulates social and educational communication among students when working in small participatory groups (Ahmed, 2014).

The flipped learning strategy has great importance, which helps the student face the difficulties and problems they face in performing some of the tasks and activities assigned to them. Thus, it helps them raise their level of educational attainment by giving students the opportunity to re-watch the videos to understand and clarify them more (Bergmann \& Sams, 2012; Johnson, 2012).

The problem that science education suffers from lies in the aspect related to the teaching models and strategies and methods used by teachers as they provide educational learning materials in most cases in a traditional, dry and dull way, this resulted in low results in the level of educational attainment and a lack of motivation of students towards learning science and forming negative attitudes towards 
school. Whereas science is one of the primary subjects that need modern strategies that keep pace with the technological revolution and technology that the world is witnessing today, the researcher noticed, through her supervision of the field training students in the college, that technology tools are not used in the teaching process in a large way. There is a lack of diversity in teaching strategies. Accordingly, the current study sought to uncover the effect of learning based on the flipped learning strategy on developing motivation to learn, and specifically, the current study tried to answer the following question:

What is the flipped learning strategy's effect on developing the motivation to learn among female students in the science subject compared to the usual method?

\subsection{Importance}

This study's importance stems from the fact that it contributed to preparing a plan for learning by means of flipped learning, how teachers use it, and how to prepare a tool to measure the motivation to learn among students. This study also dealt with the basic stage that must be given great attention because the learner is in the stage of direct sensory processes in which he needs to link the abstract theoretical material to something tangible and familiar.

\subsection{Procedural Definitions}

\subsubsection{Flipped Learning}

Sharman (2015) defined it as the type of learning in which the regular class or lecture is converted through available and appropriate technology into recorded lessons that are placed on the Internet. So that students can reach it outside the classroom to make room for various activities, active learning, and optimal use of learning time in classrooms; and it is defined procedurally:- An interactive web-based learning environment that contains video clips, educational flashes, presentations, and worksheets that can be prepared in different styles and methods as learning tools, where the students watch the lessons in their homes before class time while the teacher uses the time in the classroom to provide an active, interactive learning environment in which the students are guided and applied what they have learned.

\subsubsection{Motivation to Learn}

It is the desire that directs pupils' activity to exert more effort, perseverance, focus, and attention in learning and enjoying science, and overcoming the difficulties that may face them during the learning process (Magdy Ismail, 2009). Procedurally, it is the total score that the student gets in the motivation to learn scale.

\subsubsection{The Usual Method}

It is a teaching method in which the teacher uses the method of presentation, lecturing, oral discussion, and asking limited knowledge questions. The teacher here has a large role, and the student is a knowledge recipient without having a role in reaching this knowledge.

\subsection{The Study Determinants}

The generalization of the study results is limited to the following determinants:

- The study is limited to a unit from the science book for the seventh grade and to students of the seventh grade in the Directorate of Education in the Governorate of Ajloun. Therefore, it is difficult to generalize its results to other students, units, or other grades. 
- The extent of acceptance of the validity and reliability of the study tool used and the extent of cooperation of students in responding to this tool.

- This study is limited to female students only, not to males, which hinders generalizing its results to males.

\section{Previous Studies}

Al-Shammari and Al-Massad (2019) conducted a study to identify the effect of using the flipped classroom strategy on the academic achievement of informatics subject among eleventh-grade secondary school students in the State of Kuwait and the drive towards learning it. The sample consisted of 62 students from the eleventh grade who were chosen by the intentional method' The study tools were represented in an achievement test and a measure of motivation towards learning informatics material, and the results showed that the flipped classroom strategy indicated positive and significant application to raise the level of achievement of the learner.

Al-Duwaili and Al-Talaha (2020) conducted a study to uncover the effect of using flipped learning on developing self-organized learning skills among second-grade intermediate students in the subject of social and national studies. In addition to knowing the difference in the impact of using the flipped learning strategy according to the difference in the achievement level, the study sample consisted of 62 students in the second intermediate grade to achieve the study's objectives. A study unit was reformulated according to the flipped learning strategy and the self-organized learning scale was prepared. The results showed statistically significant differences in the self-organized learning scale in favor of the students who studied by the flipped learning method.

Al-Mashni (2015) conducted a study to investigate the effect of flipped learning on seventh grade students 'achievement in science and their creative thinking. An intentional sample consisting of (57) students from the seventh grade was chosen. The researcher used an achievement test and Torrance test for creative thinking, and after applying the study tools, the results showed that there are statistically significant differences in the achievement test in favor of the experimental group.

The study of Yapici \& Akbayin (2010) aimed to measure the effect of flipped learning for biology subject on high school students 'achievement and their attitudes toward using the Internet. And the study sample consisted of (107) male and female students of the ninth grade of Anatolia Ayyad High School in Turkey. The researcher used an achievement test and an attitude scale, and the results of the study showed that there are statistically significant differences between the mean scores of the two groups of the achievement test and the attitude scale in favor of the experimental group.

While the study of Al-Zein (2015) aimed to measure the flipped learning strategy's effect on the academic achievement of the students of the College of Education at Princess Noura Bint Abdul Rahman University, the study sample consisted of (77) female students of the College of Education, and the results showed a high level of effectiveness of flipped learning in improving students 'academic achievement.

The study of Glynn (2013) tried to verify whether the flipped learning led to an improvement in academic achievement and students attitudes toward a chemistry course. The study sample consisted of (22) male students (24) female students from the University of Montana, USA. The study results indicated that there were no statistically significant changes in students 'achievement of the chemistry course.

Marlowe (2012) conducted a study to investigate the effect of flipped learning and the related difference in student achievement rates and stress levels that they may be exposed to during teaching. The study sample consisted of (19) male and female students studying the Societies and Ecosystems course from the eleventh grade students in Montana's US state. The study results showed a decrease in the level of stress among students who study in flipped classes compared to other classroom environments, and they showed their positive attitudes towards flipped learning.

As for the study of Al Fahid (2014), it aimed to identify the effectiveness of flipped learning and its effect on female students' achievement of the preparatory programs at Imam Muhammad bin 
Saud Islamic University and their attitudes towards the university classroom environment in the English Grammar course. The study sample consisted of (42) female students, which were divided equally into a control group and an experimental group. The results showed that there were statistically significant differences between the mean scores of the two groups for the students' attitudes scale in favor of the experimental group.

And Sanders (2014) conducted a study to uncover the effect of flipped classrooms on academic achievement and critical thinking skills of high school mathematics students. The study sample consisted of (45) high school students, and to achieve the study's objectives, an achievement test and a critical thinking skills test were used. The study results showed no statistically significant differences in academic achievement and critical thinking skills between the two study groups. That is, the flipped classes were not a significant factor in increasing students 'academic achievement, nor in developing their critical thinking skills.

Youssefzadeh and Salimi (2015) conducted a study to determine the effect of flipped learning on the achievement of Iranian students. Five teachers were recruited, and each teacher taught two classes, one of who taught traditionally and the other taught with flipped learning. The results showed that there were statistically significant differences between the mean scores of the control group and the mean scores of the experimental group in favor of the experimental group.

Haroun and Sarhan (2015) conducted a study to uncover the effectiveness of flipped learning in the achievement and performance of e-learning skills among students of the College of Education at Al-Baha University in Saudi Arabia. The study sample consisted of (115) third-year students at the College of Education, and the results showed statistically significant differences in the mean scores of the experimental group that studied with flipped learning and the average scores of the control group that studied the traditional method. The researcher noticed through this study that there is a positive effect of using flipped learning among students in various fields, and despite the positive results of these studies, there are studies that have shown the opposite of previous results, as in the study (Saunders, 2014) (Glynn, 2013).

In addition to that, the researcher noticed, within the limits of her knowledge, the lack of studies directed towards the use of flipped learning in developing motivation to learn, so this study made a modest contribution to bridging this scarcity.

\section{Method}

\subsection{Sample}

The study sample consisted of seventh-grade female students in Sakhra Secondary School for Girls affiliated to the Education Directorate in Ajloun Governorate. The school was deliberately chosen because the researcher was in direct contact with her. The school director and the science teacher in it also showed a willingness to apply the study, which facilitated the implementation and follow-up process; and the number of students reached (8o) students, and it was divided into two classes, and it was distributed on the two random assignment treatment methods. One of the classes studied using the flipped learning method, and the other class was studied in the usual way.

\subsection{The Research Tool}

The researcher prepared a scale of motivation to learn based on what was mentioned in the educational literature and previous studies and measures of motivation prepared in advance, such as (Al-Rashoud, 2013); (Qatami, 2005) (Al-Maghribi, 2003); (Al-Qarra'a, 2003).

The researcher concluded that a scale consisted of (32) items, in its final form, Appendix (1), the items dealing with the student's position on the science classes, and the topics presented. This test's items are responded to according to Likert's five-point grading (strongly agree, agree, not sure, disagree, strongly disagree). 


\subsubsection{The Test Validity}

The validity of the scale was verified before its application by presenting it to a group of specialized arbitrators, Faculty members specializing in science curricula and teaching methods, measurement and evaluation, and educational psychology educational supervisors, and a group of masters holders in science teaching, they were asked to judge the test in terms of the appropriateness of the paragraphs to measure the motivation to learn and the clarity of the paragraphs in terms of the accuracy of the wording and the integrity of the language, and the suitability of the paragraphs to the age level of the students. The arbitrators were also asked to propose any other modifications they deem necessary to be made on the examination. The arbitrators have supported the suitability of the scale for the purposes of the study.

\subsubsection{The Test Reliability}

The reliability of the test was verified by applying it to the pilot sample of the seventh-grade students from outside the sample members, after which the researcher calculated the Cronbach Alpha coefficient to verify the consistency of the tool and found that it is equal to $(0,81)$ and this value is considered acceptable for the purposes of this study.

\subsection{Procedures}

This study was carried out by performing the following procedures:

- The educational material for the fourth unit of the science book for the seventh grade was prepared, and the title of this unit (Classification of living organisms and their reproduction) A guide for teaching subjects was developed, as it contained instructional plans that included how to prepare and conduct the lesson and means of evaluation for that method, as in Appendix (). These plans were presented to a group of qualified and experienced arbitrators, and after that the necessary amendments were made to these plans.

- A scale was prepared to measure the motivation to learn science among students, and the validity and reliability of this scale were verified.

- Determining the school in which the study was carried out, which is Sakhra Secondary School for Girls.

- Meetings were held with the science teacher to train her on how to teach using the educational guide prepared for the experimental group.

- The Pretest was applied to the experimental and control groups.

- The implementation of the study continued for a period of two months, with four lessons per week.

- The post-application was applied to the experimental and control groups.

- The students' responses to the pre and post-tests were corrected; the results were finalized and analyzed using appropriate statistical analyzes to find indications of the differences between the two groups' performance in the aforementioned test.

\section{Results}

The following is a presentation of the findings

Results related to the study question:

- What is the flipped learning strategy's effect on developing the motivation to learn among 7 th-grade students in the science subject compared to the usual method?

To answer the question, the means and standard deviations of the study individuals' scores were calculated on the motivation to learn scale, as shown in Table (1). 
Table 1: Means and standard deviations of the female students' pre and post scores on the motivation to learn scale according to the teaching method variable

\begin{tabular}{|c|c|c|c|c|c|c|}
\hline \multirow[b]{2}{*}{ Group } & \multicolumn{3}{|c|}{ Pre scale } & \multicolumn{3}{|c|}{ Post scale } \\
\hline & $\begin{array}{l}\text { The number of } \\
\text { group members }\end{array}$ & $\begin{array}{l}\text { Arithmetic } \\
\text { average }\end{array}$ & $\begin{array}{l}\text { standard } \\
\text { deviation }\end{array}$ & $\begin{array}{l}\text { The number of } \\
\text { group members }\end{array}$ & $\begin{array}{l}\text { Arithmetic } \\
\text { average }\end{array}$ & $\begin{array}{l}\text { standard } \\
\text { deviation }\end{array}$ \\
\hline Experimental & 40 & $164 \cdot 76$ & $28 \cdot 67$ & 42 & $185 \cdot 62$ & $30 \cdot 87$ \\
\hline Control & 40 & $162 \cdot 64$ & $34 \cdot 42$ & 42 & $166 \cdot 57$ & $33^{\prime} 78$ \\
\hline
\end{tabular}

It is noted from Table (1) that the arithmetic average of the marks of the students who studied using the method of dispersal damage on the scale of attitudes towards science reached (185.62), which is higher than the arithmetic average of the marks of female students who studied using the standard method, which amounted to (166.57) To find out whether the differences between these averages are statistically significant at the level of significance $(\alpha \leq 0.05)$. An analysis of variance accompanying (ANCOVA) for the marks of the students of the two study groups was performed on the scale of attitudes towards science according to the teaching method's variable. Table No. (2) shows the results of this analysis:

Table 2: The results of the accompanying analysis of variance (ANCOVA) for the grades of female students on the dimensional scale of motivation to learn science according to the teaching method variable

\begin{tabular}{|l|c|c|c|c|c|}
\hline The source of contrast & Sum of squares & $\begin{array}{c}\text { Degrees of } \\
\text { freedom }\end{array}$ & $\begin{array}{c}\text { Average of } \\
\text { squares }\end{array}$ & $\begin{array}{c}\text { The computed (Q) } \\
\text { value }\end{array}$ & $\begin{array}{c}\text { Statistical } \\
\text { significance }\end{array}$ \\
\hline Associated variable & 69322,17 & 1 & 69322,17 & 339,65 & 0.000 \\
\hline Method & 6135,34 & 1 & 6135,34 & 30,06 & 0.000 \\
\hline Error & 16532,03 & 81 & 204,10 & & \\
\hline Total & 93473,24 & 83 & & & \\
\hline
\end{tabular}

It is noticed from Table (2) that there were statistically significant differences at the level of significance $(\alpha \leq 0.05)$ between the arithmetic averages of the marks of the study individuals on the scale of attitudes towards the dimensional sciences due to the variable of the teaching method, where the value of the statistic $(P)$ for the teaching method variable reached (30.06) This value is statistically significant at the level of significance $(\alpha \leq 0.05)$, and to know in favor of which of the two methods are the differences attributable, the modified arithmetic averages of the marks of the female students of the study members were calculated on the motivation scale to learn the post sciences. Table (3) shows these averages.

Table 3: The adjusted means for the experimental and control groups

\begin{tabular}{|c|c|}
\hline Group & Adjusted mean \\
\hline Experimental n $1=40$ & $184 \cdot 65$ \\
\hline Control n $2=40$ & $167 \cdot 54$ \\
\hline
\end{tabular}

It is evident from Table (3) that there is a statistically significant difference at the level of significance $(0.05 \leq \alpha)$ between the members of the two groups on the scale of attitudes towards science and the difference was in favor of the experimental group as the modified arithmetic mean of the marks of the experimental group was $(184,65)$ and the control group $(167,54)$ which means that learning in a deviated distraction way has an effective effect on attitudes towards science among seventh grade students. 
The results of the study question showed that there is a statistically significant difference $(0.05 \leq \alpha)$ between the average performance of the control and experimental group in developing motivation to learn and this difference was in favor of the experimental group that learned according to the method of flipped learning and this result is consistent with the study of each (Glynn, 2013; Marlowe, 2012) and the result can be interpreted as follows: In traditional lessons, the teacher relies heavily on explanation and lecturing, and he may not find enough time to receive students' inquiries and questions sufficiently about some concepts compared to students of flipped learning in which the teacher invests class time to listen to students 'questions and queries about what they have heard or seen at home, which enriches their information and helps them increase their motivation to learn, also, in the regular class, the absence of a student from the class may cause a problem, and the teacher may not have another time to re-clarify the concepts that were previously explained, this problem goes beyond the nature of flipped learning, so the student can follow up on the lessons he missed through the video prepared for this lesson, the flipped learning found favor and acceptance from the students because they learned with new strategies that stimulated their enthusiasm and their desire to learn better and the diversity in activities and tasks such as videos, presentations and working papers had a positive effect in increasing students 'motivation to learn and support the spirit of cooperation and partnership with peers.

The flipped learning method provided the students with a rich environment characterized by fun, excitement, and cooperation among the same group members, thus achieving active participation by the student. The teacher's abandonment of the traditional role as a controller and owner of information, which could be considered a possible explanation for the improvement of students' motivation to learn. It also enabled the students to integrate and indulge in working in science classes and make them feel self-satisfied with what is going on inside the class and increase their appreciation for the benefit of what they do. This may have increased their self-confidence and pride in what they possess, they increased their love for science subjects and affected their motivation to learn science positively.

\section{Conclusion}

The concept of inverted learning is the heart of the learning tasks between the classroom and the home, so that the teacher makes use of modern technologies and the Internet to prepare the lesson, through a video tape, to inform the student of the teacher's explanation at home, and then perform the activities that were homework in the class, which enhances his understanding of the scientific material. The use of inverted learning came to change the established view in the minds of some, which is represented by changing the stability on one strategy, and replacing it with a new strategy in line with the successive technological revolution in the current era, the computer is considered one of the most effective technological means in the educational process, and with inverted learning, it has taken a pivotal role through watching educational videos and discussion relationships between students.

\section{Recommendations}

1. To conduct more studies to test the effectiveness of this method in learning science in other classes and stages of study and in learning subjects other than science.

2. To conduct rehabilitative training programs for teachers based on the application of models of flipped learning to be used in all schools in the Kingdom.

3. Work to raise the learner's morale and motivation and help them learn how to deal with information. 


\section{References}

Ahmed, E. (2014). The flipped classroom strategy's effect through mobile learning on developing the skills of filming television programs among graduate students, the International Conference on E-Learning in the Arab World, the Egyptian University for E-Learning, 24-26 June 2014.

Johnson, G. (2012). Students' perspectives on flipped class. Unpublished Master thesis, University of British Columbia.

Al-Rashoud, M. (2013). Methods of Treating the Low Motivation of Students Departments of Forensic and Arabic Sciences in the Governorates of Hawtat Bani Tamim and Al Hariq, were recalled on May 29.

Al-Khalili, Y. (1996). The implications of constructivist philosophy in the teaching of sciences. Education Journal, 25, (116), 255-270.

Al-Sharman, A. (2015). Blended learning and flipped learning. Amman: March House for Publishing, Printing and Distribution, Amman.

Al-Shahrani, A. (2014). Flipped learning in university education. A scientific article in the prospect's magazine of the Saudi Society for Educational and Psychological Sciences issued on January 2016 AD, Issue 49, College of Education, King Saud University, Kingdom of Saudi Arabia.

Zaitoun, A. (2004). Methods of teaching science. Amman: Sunrise Publishing House.

Al-Feki, A. (2011). Blended Learning Instructional Design Multimedia - Innovative Thinking. Amman, House of Culture for publication and distribution.

Al-Gararah, A. (2003). The Effect of Using Multiple Educational Media on Academic Achievement and The Motivation for Learning in Chemistry for High and Low Achievement Students of Ninth Grade Basic, Unpublished PhD Thesis, Amman Arab University, Amman - Jordan.

Qatami, N. (2005). Teaching Thinking, 1st Edition, Amman, Dar Al-Fikr for Publishing and Distribution.

Magdy Ragab, I. (2009). The Effectiveness of E-Learning Methods in Sixth Grade Pupils' Achievement and Their Motivation towards Learning Science, Journal of Scientific Education, Vol. 12, Issue 1, pp. 17-71.

Al-Maghrabi, K. (2003). The relationship between learning motivation and both achievement and orientation towards school among students of the eighth and tenth grades in public schools in Jericho, unpublished MA thesis, Al-Quds University, Palestine.

Haroun, A. \& Sarhan, M. (2015). The Effectiveness of the flipped learning Model in Achievement and Performance of E-Learning Skills for Undergraduate Students at Al-Baha College, The First International Conference of the College of Education, Future Prospects, King Abdul-Aziz Cultural Center, Kingdom of Saudi Arabia.

Al-Huwaidi, Z. (2005). Educational games, strategy for developing thinking, Al Ain: University Book House.

Al-Duwaili, F. \& Al-Talaha, H. (2020). The effect of using the flipped learning strategy on developing selforganized learning skills among intermediate second students in the subject of social and national studies in the Kingdom of Saudi Arabia, The Islamic University Journal for Educational and Psychological Studies, Issue 1, Volume 28.

Al-Shammari, T. \& Al-Massad, A. (2019). The Effect of Using the Flipped Classroom Strategy on Academic Achievement and Motivation Toward Learning Informatics Subject for Eleventh Grade Secondary Students, Journal of Educational and Psychological Studies - Sultan Qaboos University Issue 1, Volume 13.

Bergmann, J. \& Sama, A. (2012). The short history of flipped learning. "flipped learning network.

Brame, C. (2013). flipping the classroom, retrieved 15 November, 2015 from http: //cft.vandevbilt.edu/teaching guides/ teaching -activities /flipping -the -classroom/.

Butt, A. (2014). Student views on the use of lecture time and their experience with a flipped classroom approach social sciences comprehensive works. ProQuest central.

Johnson, L. \& Renner, J. (2012). The flipped classroom model's effect on A secondary computer Application course: student and teacher perceptions, questions and student achievement dissertation submitted to the faculty of the college of education and human development of the University of Louisville.

Marco, R. (2010). Using video lectures to make teaching more interactive International Journal of Emerging Technologies in learning, 5(2),45-48.

Yousefzadeh, M. \& Salimi, A. (2015). The effect of flipped learning (revised learning) on students' learning comes from advances in language and literacy studies 6(5),3-12. 


\section{Appendix 1:}

The following scale contains (30) items that measure motivation to learn science, each of which in the answered questionnaire has a scale of five degrees, expressed in by (strongly agree, agree, neutral, disagree, strongly disagree).

1. I feel happy when I'm in class.

2. I feel happy when I do my homework.

3. I find it difficult to concentrate when preparing for the exam.

4. I am interested in excel in my studies.

5. Enjoy reading external books.

6. Outdoor activities and games attract me more than studying.

7. I am late for my colleagues in completing class work.

8. My class students are smarter than me.

9. I am looking forward with interest to continue my university studies after graduating from school.

10. I hate sticking to school rules.

11. It is difficult for me to pay attention to the teacher's explanation and follow it up.

12. I would love for all my classmates to be satisfied with me.

13. It is difficult for me to quickly befriend classmates.

14. I feel that adhering to the school rules creates a comfortable academic atmosphere.

15. I prefer for the teacher to give us difficult questions that need thinking.

16. I do a lot of school activities and student societies.

17. I prefer to do the work in a group of colleagues than to do it alone.

18. I feel satisfied when I develop my school knowledge and skills.

19. My father is interested in realizing my feelings towards school.

20. I feel that most of the lessons offered by the school are not exciting.

21. My dad doesn't care about my school grades.

22. I am glad that the rewards are given to students with the amount of effort expended.

23. Working with classmates enables me to get higher grades.

24. Collaborating with my classmates in doing my homework is of benefit.

25. My interest in some academic subjects leads to the neglect of everything around me.

26. It is difficult for me to pay attention to the teacher's explanation and follow it up.

27. I feel that most of the lessons offered by the school are not exciting.

28. I would love for all my classmates to be satisfied with me.

29. I will be happy during the exam.

30. It was astonished that the students were actively involved in their studies.

Appendix 2: Planning with a flipped learning strategy

Subject: Invertebrate Animals

Subject: Science

Grade: VII

Time Required: 40 minutes

First: The Goals

- The student should explain what is meant by invertebratesj

- To mention the classifications of invertebratesj

- To mention examples of these classifications j

- That the student sees samples of the environment on invertebratesj 


\section{Means and sources:}

Blackboard, textbook, worksheets, cards, pictures and drawings, video that contains a lesson entitled invertebrates, social media, information storage media such as (CD), the Internet.

\section{Lesson implementation stages:}

The first stage (pre-class)

The teacher directs the students to watch the video of the lesson and distribute it to the students through a CD or WhatsApp.

Distributing the video to the students before the face-to-face meeting the day before the lesson.

The students record their observations and inquiries on the video they watched, write the questions and bring them to the classroom.

The second stage: (inside the classroom)

- The teacher makes sure that the students watch the video.

- The teacher receives the students 'questions and comments about the subject and conducts a dialogue and discussion with the students.

The third stage: (Evaluation)

- The teacher makes a short test that includes questions on the educational material in the video.

- Distribution of working papers to the students. 